\title{
Memoriales modernos: inflexiones en la construcción de la memoria colectiva $^{1}$
}

Modern memorials: inflections in the construction of collective memory

\author{
Noelia Cardoso \\ Universidad de Buenos Aires, Argentina \\ silose2301@gmail.com
}

\section{RESUMEN:}

Este artículo aborda los memoriales modernos a partir de las prácticas inapropiadas de algunos de sus visitantes. A través del registro de los modos de uso y promoción de los lugares de memoria y los consiguientes cuestionamientos y debates por parte de los estados, artistas e intelectuales, se propone repensar estos espacios de memoria reciente sus estéticas y las normas que los rigen. De lo que se trata es de desmontar el binomio respeto-falta de respeto entendiendo que las formas no son reaseguro de la comprensión de los sucesos recordados sino un requerimiento que sostienen un orden aparente. Se espera que las presentes reflexiones sean un aporte para fortalecer la memoria colectiva y el rol del arte contribuyendo a los debates sobre la transmisión del pasado y la musealización de la memoria.

Palabras ClaVE: Lugares de memoria, Memoriales modernos, Arte, Transmisión.

\section{Abstract:}

This article focuses on the modern memorials based on the inappropriate practices of some of its visitors. Through the registration of the modes of use and promotion of memory places and the consequent questions and debates by goverments, artists and intellectuals, it is proposed to rethink these places of recent memory their esthetics and the rules that govern them. What is involved is to dismantle the respect-disrespect binomial, understanding that the forms are not reinsurance of the understanding of the events remembered but a requirement that sustains an apparent order. The present reflections are expected to be a contribution to strengthen the collective memory and the role of art contributing to the debates about the transmission of the past and the musealization of memory.

KEYWORDS: Memory places, Modern memorials, Art, Transmission.

Por respeto se prohíbe andar en bicicleta, patines, treparse y transitar con perros sin correa Parque de la memoria, Buenos Aires, Argentina

Como docente en la enseñanza media observé cómo dos alumnos preparaban un machete para una prueba de historia y uno de ellos anotaba "desaparecidos-30.000" Dario Sztajnszrajber

Las dos citas que inician este apartado son el puntapié inicial de este texto que pone en relación la institución museal y las prácticas de los sujetos; la preocupación gira en torno a la tensión entre la norma que modela el recuerdo y el desconocimiento que reporta quien transita el espacio memorial. Para dar cuenta de esta problemática, se toman tres inflexiones ${ }^{2}$ que demarcan la construcción de la memoria colectiva y estructuran la repartición de lo sensible. La primera inflexión refiere al diseño arquitectónico del espacio que configuran los museos y parques de la memoria; la segunda inflexión a los modos designados controversiales de transitar y percibir dichos lugares. Por último, una tercera inflexión refiere a la transmisión del acontecimiento. Estos puntos de torsión revisten una mutua implicación y emergen a partir de la condonación pública de ciertas conductas de quien visitan parques y museos de la memoria. ¿Cómo son 
las modalidades estéticas que se proponen para construir la memoria?, ¿Cuál es el uso de los espacios memoriales?, ¿"Nunca más"3, pero cómo? A partir de estos interrogantes se espera contribuir de manera crítica a los debates sobre la musealización de la memoria del pasado reciente.

Se parte de las reflexiones epistemológicas de Boaventura de Sousa Santos (2007) quien cuestiona la construcción hegemónica de lo social y señala que su configuración dominante se asienta sobre "ausencias". Es por eso que frente al paradigma del progreso y su construcción unívoca de lo real propone una "ecología de saberes" cuyos elementos contrarresten aquellos naturalizados. Para desarmar el tiempo lineal, el saber y el rigor, la naturalización de las diferencias y el establecimiento de jerarquías y escalas dominantes sumadas al productivismo capitalista, plantea la convivencia de saberes, temporalidades, escalas y productividades. Este ejercicio que incluye relatos dispares y actores sin protagonismos pero con presencias, posibilita el corrimiento de la narrativa sacralizada, la saturación de sucesos impactantes y aleccionadores e incorpora las contradicciones y sus puntos velados.

Asumir esta mirada para comprender la relación entre la estatización de la memoria y el uso que los visitantes le dan a los memoriales es un intento incómodo por horadar lo que Halbwachs llama "marcos sociales de la memoria" (Halbwachs, 1994), estructuras que guían el recuerdo colectivo, complementan, acoplan, reponen los procesos de rememoración individual y estimulan ciertos repertorios sobre lo recordado. Su prevalencia se afianza por la identificación de determinados grupos sociales que fortalecen su propia subsistencia por lo que, la selección de sucesos históricos, deviene en "operación" (Ricoeur, 2008). Ahora bien, el control sobre el pasado a través de las narrativas oficiales devela su cualidad de "fetiche" (Grüner, 2006) ya que la construcción de la memoria histórica se da en el plano de la imagen y no de la materialidad. La representación del pasado traumático, el detalle y caracterización de ciertas vivencias prima por sobre el debate de las condiciones sociales que posibilitaron esos sucesos. Entonces se plantea el desafío: ¿Puede la memoria del capital exponer de manera sostenida los andamiajes de la producción y reproducción del horror que él mismo provoca?, ¿Cuáles son esas estéticas que lo sostienen?.

Si bien lo social es estructurante, existe una separación que provoca la experiencia individual, marca temporalidades y define la recepción del acontecimiento. La selección del acervo cultural que construye y estimula un pasado común puede ser alterada por la vivencia personal en el presente, de manera imprevista, vital. El movimiento continuo de engarce entre lo social/pasado invididual/presente, en las reflexiones de Raymond Williams (1977/2009) configura una estructura del sentimiento donde la subjetividad rompe el espacio común y lo llena de experiencias que conviven, se superponen, colisionan y retornan a lo social transformándolo. Abordar el objeto museo, y en este caso un tipo particular de institución museal como es el memorial, implica observar una distribución desigual en la conformación del mundo de la sensibilidad común (Ranciere, 2014). En este sentido, Ranciere propone la estética política como acción que promueve nuevos modos de mirar y decir, cuerpos, espacios y tiempos que posibilitan mayores grados de igualdad y subvierte la repartición jerárquica y excluyente que rige el gobierno de lo sensible.

La memoria definida como fragmento, marco, cultura fetichizada, atravesada por la experiencia mediata que la reproduce, la altera o la ignora, expone una repartición de lo sensible que es también constituida por el espacio donde se produce. En este sentido, el museo es visto como lieux de memoria (Nora, 2008) donde se condensan elementos que son parte del recuerdo colectivo y cuya configuración, a su vez, resulta de sus capas de significación. Es por ello que se tiene en cuenta las transformaciones del rol del museo que sintetiza Andreas Huyssen (2007) institución que pasó de ser salvaguarda de la cultura de las élites a reservorio de "lo nacional" para concluir como objeto de consumo de masas reconvirtiéndose en una "museomanía", parte central de la industria cultural y turística de los Estados-Nación. Este recorrido permite ver en el museo los trazos que las culturas y el desarrollo que el mercado le atribuyeron y apuesta al uso de dichos lugares para reflejar las contradicciones y desplegar sus heterogeneidades.

A la yuxtaposición de funciones del museo descrita, se agrega la configuración de la institución museal como "aparato estético" (Deotte, 2007) lo que marca un territorio que transmite el acontecimiento y 
determina sensibilidades y modos de vivenciar épocas que generan comunidad. Esta propiedad modalizadora que resulta independiente del destino de la obra agrega la cuestión sobre el tipo de democracia que potencia dicha institución. Walter Benjamin (1934/1975) advertía que la distancia de la obra del contexto y su desacralización son efectos negativos de la modernidad pero encontraba una potencia en la utilidad política del arte en relación a las condiciones de producción del artista y su capacidad de confrontar, es decir, de "desilusionar" al público exponiendo la realidad. Bajo esta égida, Didi-Huberman (2014) retoma esta posición sobre el arte y su rol político para interpelar la representación de los pueblos y su memoria en un mundo contemporáneo donde la reproducción y repetición de imágenes icónicas pone en peligro su esencia.

Estas disposiciones no implican señalar un carácter negativo de las estructuras museales sino una oportunidad para repensarlas. La preocupación sobre la transmisión del acontecimiento y su representación como sostén de la vida democrática, en el trabajo de Régin Robin (2014) se materializa en la recopilación de performances que den cuenta de los vacíos y ausencias; en línea a la propuesta de Benjamin, promueve la rememoración como "tercer-espacio" donde recordar se de a partir de las ruinas y la carencia. Si al decir de Ricoeur la memoria es un trabajo, el museo como distribución de sensibilidades, aparato, o isla temporal permitiría cuestionar de manera provocativa aquellos modos de construcción de memoria homogeneizantes, estabilizados y restringidos al grupo social que lo arma y propone una estética que lo sustenta.

\section{VENUSTAS, FIRMITAS, UTILITAS}

Parte de los debates de opinión que gravitan sobre los parques de la memoria (Da Silva Catela, 2014; Schindler, 2009; Jelin y Langland 2003) refieren a la relación entre su diseño -materiales, estética, niveles de abstracción- y su uso, del cual se espera comparta la propuesta de recogimiento y compromiso con los sucesos conmemorados. Sin embargo, estos espacios abiertos también plantean una superposición de sentidos entre quienes lo proyectan, la concepción de las diferentes gestiones gubernamentales y el público que asiste. En algunos casos se inicia en la propia denominación de "parques", lo que habilita el sentido literal de la denominación. Así lo reflejan varios comentarios de los Local Guide en el sitio de Google sobre el Parque de la Memoria en Buenos Aires donde es recurrente la recomendación del espacio como lugar de esparcimiento y exaltan la apuesta paisajística por sobre el rol memorial:

Excelente lugar para salir a caminar, rodar en bicicleta, etc. Es un lugar al aire libre frente al río, muy tranquilo y hermoso. La entrada es gratis. El lugar está limpio y cerca de paradas de colectivos. Recomendado 100\%”. (SH, Local Guide, agosto 2019)

Es un lugar muy tranquilo para ir a disfrutar la vista del río y los aviones, al no haber juegos para niños prácticamente no hay nadie que moleste la mayoría es gente joven. Llevar para tomar y comer algo, una manta para recostarse o simplemente sentarse que hay demasiado lugar. Los días ventosos uno se puede refugiar tras esas paredes grises. Los baños están bastante bien”. (CG, Local Guide, julio 2019).

Otro ejemplo, en la página de turismo, en su sección atractivos del Gobierno de la Ciudad Autónoma de Buenos Aires ${ }^{4}$, el parque se promociona dentro de la sección "Espacios verdes, qué hacer”. En el apartado "recorrido de la memoria" donde se agrupan los sitios de la memoria reciente se destaca que:

Es también un lugar intervenido por el arte contemporáneo: la producción estética nacional e internacional de artistas de gran renombre y compromiso dotan al sitio de una capacidad de reflexión intensa. Es también un lugar de visita habitual de presidentes y mandatarios de todo el mundo.

En comparación con la descripción de la sección "Patrimonio cultural" de la misma $W e b$ se destaca la calidad de lo "internacional" -artistas y visitas de jerarquía- como estrategia de promoción turística. Se observa así un discurso institucional que se adapta para atraer a los diversos visitantes que buscan conocer los lugares icónicos de la ciudad.

La ilusión de un espacio de placer ganado a la ciudad reconvierte el sentido político del memorial. Amplias extensiones solitarias que combinan espacios verdes austeros, con emplazamientos abstractos, bloques de 
hormigón y grandes esculturas geométricas de acero, hierro y bronce no son asumidos por muchos visitantes como el modo reflexivo de asir las narrativas del pasado reciente. El alto que generan los parques memoriales en la dinámica de las urbes con el fin de promover la calma y el encuentro, provoca una armonía con el entorno que los reconvierte en lugares de recreación o escenarios para la propia exhibición artístico-deportiva tales como selfies, videos musicales, parkour o skateboarding.

Las regularidades en las prácticas que privilegian los requerimientos de quienes los transitan y subversionan los espacios de memoria, muestran una inversión en la relación museo-visitante donde es el sujeto quien promueve su protagonismo por sobre el memorial y el uso literal de sus formas por sobre la representación que guía el sentido propuesto de los objetos artísticos construidos. Sumado a esto, la fuerza de lo allí recordado se traslada a quien se registra y el espacio es reasignado a escenario-símbolo. El "Yo estoy aquí" cambia la impresión sensible de la obra hacia el estado emocional del sujeto presente quien muestra prácticas lúdicas, hedonistas y alegres. En contraposición, la denuncia y la interpelación a dichas conductas deviene en la promoción racional del recuerdo como deber colectivo y el recogimiento frente al reconocimiento que designa el trauma en la historia de la civilización.

Como parte de estas denuncias se realizó un rastreo de publicaciones sobre críticas y sanciones logrando agrupar estos avisos en tres reacciones: imputaciones, propuestas para visibilizar, aleccionar y una defensa de la libre circulación por el memorial. Del primer grupo de argumentos que se señalan como falta de respeto se conocen por la difusión de las decisiones punitivas del Estado, instituciones museales o su condonación en las redes. En el año 2015 el gobierno ruso encarceló a un grupo de jóvenes por hacer Twerking -baile del perreo en la denominación local- en el Memorial de la Segunda Guerra Mundial en Novorossiysk, al suroeste de la ex potencia soviética 5 . En el 2016 la empresa Niantik creadora del Pokemon Go, juego de realidad aumentada cuyos jugadores deben recorrer distintos puntos de sus barrio, ciudades y localizar a los variados personajes que se les aparecen, ateniendo a las denuncias de los museos, debió sacar de su programa los marcadores del Museo de la Memoria del Holocausto en Washington, Estados Unidos y el Museo de Auschwitz, en Polonia ${ }^{6}$.

Del segundo conjunto de críticas como propuestas de concientización se mencionan iniciativas y reflexiones independientes. El film Austerlitz del cineasta bielorruso Sergei Loznitsa cuya intención fue poner en debate la apertura al turismo de los campos de concentración a partir de una cámara que registra el paso de los visitantes. A partir de este dispositivo, hizo visible la banalidad en algunos de los comportamientos de quienes visitan el centro Sachsenhausen en Oranienburg, Alemania. Sumado a esta implicación artística pero en tono de denuncia, se menciona el proyecto Yolocaust (Yolo/solo se vive una vez) del artista germano-israelí Shahak Aspira. La muestra circula en redes sociales y trabaja a partir de las fotos que los turistas se toman y suben a la red riendo, haciendo piruetas y gestos frívolos sobre los bloques de hormigón del Monumento al Holocausto en Berlín. Aspira realizar una superposición de imágenes -de tiempo y espacio- para trasladar esos gestos y actitudes a las más crudas imágenes de los campos de concentración creando una sinonimia entre la representación abstracta, la escultura del parque y los retratos que registran los sucesos de la época que se rememora. El origen de este proyecto surge de una preocupación personal sobre la incomprensión del pasado por parte de las nuevas generaciones; según la definición del autor, estos monumentos representan una "brújula moral" 7.

En el mismo plano pero como crítica al propio memorial y la gestión que participó de su construcción, en el año 2010 al conocer el Parque de la Memoria en argentina el filósofo Tzvetan Todorov escribió que dicho emplazamiento carecía de contexto y que las personas allí homenajeadas estaban reducidas al papel de víctimas pasivas sin conocer su historia previa ni el motivo de su detención: "Cuando uno atribuye todos los errores a los otros y se cree irreprochable, está preparando el retorno de la violencia (...) Comprender al enemigo quiere decir también descubrir en qué nos parecemos a él." ${ }^{8}$ En este caso, la demanda por dotar al memorial de mayor referencia histórica desanda las construcciones aisladas de producción de la figura víctima-victimario y pone en protagonismo la gestión estatal que lo constituye. Bajo esta línea se inscribe la polémica de los argentinos Marcelo Brimajer y Ana Longoni; el puntapié inicial fueron las notas editoriales 
del periodista opositor en el diario Clarín donde relata su sorpresa por cierto contenido de una muestra en el Parque de la Memoria a la que asocia al relato sesgado y partidario del gobierno kirchnerista en ejercicio, reclamando el derecho a recuperar lo que denomina de manera posesiva y homogénea "nuestra memoria". Por su parte, la Doctora en arte publica una carta en la revista de artes visuales Ramona en réplica a la visión de Brimajer, señalando el recorte intencional y malicioso que no permite entender la obra en su conjunto y la independencia del proyecto por sobre el espacio institucional. Sumada a la autoría de los artistas, Longoni denuncia la operación editorial de Brimajer y desmonta su argumentación demostrando que la obra era previa al período y el prestigio en la selección de jurados que participaron en el concurso público de selección de obras. Tanto los señalamientos de Todorov como los de Brimajer soslayan el cuestionamiento sobre el resto de los memoriales y los contextos de su producción, generando la idea de que existen algunos memoriales libres de valores -e incluso ellos mismos-.

En el tercer y último grupo, se hace referencia a quien defiende la libre circulación de los memoriales. Aquí se destaca al arquitecto judío Peter Eisenman, quien diseñó el monumento al Holocausto y se pronunció en contra a la propuesta de Aspira descrita anteriormente. El autor distingue, por un lado, el monumento de los lugares donde efectivamente ocurrieron las masacres y, por el otro, el sentido que le otorgó a su construcción: “(...) Mi idea era permitir que muchas personas de diferentes generaciones, a su manera, trataran o no de estar en ese lugar. Y si quieren alardear alrededor creo que está bien. Pero poniendo esos cuerpos en las fotos,

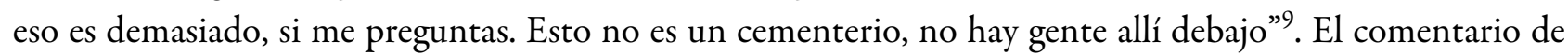
Eisenman sobre su obra en Berlín designa un giro de apertura del espacio que promueve la conciliación: habitar el memorial construido para recordar, descubrirlo, re-conocerlo o ignorarlo: "tratar de estar" con todo lo contradictorio que ello conlleve.

Las prácticas enumeradas y calificadas como indebidas permiten pensar en la vinculación del presente con el pasado y los sentidos que se proyectan a partir de la apuesta estética. Para sostenerla y contrarrestar el uso superficial del espacio, además de personal de seguridad y mantenimiento se exhiben carteles de prohibiciones y normativas que definen una forma unívoca de transitarlos donde la obediencia es percibida como sinonimia de la comprensión de los acontecimientos ${ }^{10}$. El llamado a expresar un conjunto de modos y formas determinadas en el espacio recordatorio, la calma, los gestos circunspectos y la escucha, establece los trazos de una determinada sensibilidad hacia la memoria del pasado reciente que, se cree, configuran una "estética del respeto". La preocupación por las formas de demostrar honra homogeneizando posturas es propia de los regímenes autoritarios que asocian los modos al contenido ${ }^{11}$. ¿Acaso el silencio de los visitantes garantiza la incorporación del sentido colectivo sobre la reflexión del pasado traumático?.

Además de la estructura que modela las conductas y decreta las propias de las impropias estas últimas no son exclusivas ni a este tiempo ni se circunscriben a los memoriales de historia reciente ${ }^{12}$. La distancia entre la propuesta institucional y las prácticas que la tergiversan se sostienen en templos, cementerios, monumentos y memoriales de las diversas culturas sin haber despertado mayor estupor. Esta regularidad en las prácticas de los sujetos y la poca difusión de propuestas para contrarrestarlos dispara dos puntos de reflexión referidos a la transmisión y la hegemonía del acontecimiento. Por un lado, la extrañeza que provoca el acontecimiento debe ser reformulada por las instituciones memoriales promoviendo estrategias que permitan el paso del visitante-espectador al visitante que participa; para ello, el arte debe trabajar en la generación de ausencias e incomodidades, sensibilidades que interpelen e involucren a los visitantes en la construcción de su propia memoria como parte de la comunidad.

Por otro lado, el protagonismo de la Segunda Guerra gana el mercado del recuerdo, en términos de financiamiento, construcción de memoriales, industria editorial y de investigación por sobre otras masacres que van desde el etnocidio colonial hasta el genocidio armenio, pasando por las políticas de desapariciones en períodos dictatoriales -dictaduras latinoamericanas y europeas-. Las diversas propuestas demuestran la lucha por el sostén de un consenso sobre un suceso que devino en acontecimiento y marca la sombra del posible retorno. Bajo el "nunca más" que identifica el proceso de desapariciones forzadas llevado a cabo 
por la última dictadura militar en argentina se extiende el límite que guía el por qué recordar. Desde la perspectiva asumida en este escrito, lo que realmente está en juego es la puesta pública de las condiciones de producción del acontecimiento: los intereses económicos, la manipulación política, el enriquecimiento de sectores empresarios. Es menester cambiar la producción de lo sensible para representar los hilos del poder; desandar las narraciones en términos de héroes y villanos corriéndose del relato tranquilizador que designa culpables unívocos hacia la observación de los pueblos y sus encarnaduras cuyas dinámicas siguen presentes.

\section{CONSTRUIR COMUNIDAD}

El ejercicio del análisis propuesto contrarresta las formas hegemónicas de pensar la construcción de memoria y revisita el rol de los memoriales desde un lugar incómodo. El conjunto de prácticas señaladas que refieren a pensar el diseño, los modos de transitar y la transmisión de la memoria, permitió moverse de la condena y la calificación polarizada respeto/falta de respeto para convertir lo asumido como disfuncional en materia productiva. La enumeración condujo a establecer una distancia entre lo esperable de la propuesta recogimiento, comprensión, duelo- y cierta recepción que se designó banal o irrespetuosa. La sinonimia de parques, los diseños armónicos y las tendencias artísticas con que se presentan los acontecimientos recordados son reconvertidos en un producto turístico a ofrecer por los diferentes Estados-nación o ser visitados como reaseguro de "haber estado".

Ahora bien, el libre uso y promoción de los lugares de memoria no debería ser contradictorio. De lo que se trata es de cuestionar el uso democrático del espacio memorial a partir del rescate del sentido ciudadano de compromiso con la historia. Dicha práctica es constitutiva del habitar colectivo independientemente de cómo se exprese. Se debe dejar de lado el control sobre la postura circunspecta ya que parte de una estética del respeto que no asegura la comprensión ni la práctica individual propia del sistema de consumo. Es por ello que se propone repensar los modos de internalizar el pasado, participar de la experiencia colectiva independientemente de la postura, vestimenta o acción, mover los puntos de encaje naturalizados, lo que se cree, es tarea de un tipo de arte que genere sensibilidades encontradas y exprese el conflicto de intereses.

Por último, pensar en escalas y en una ecología de la opresión requiere no circunscribir el despliegue de la memoria a un acontecimiento específico y aislado, sino establecer los rasgos que perduran sobre la desaparición del otro y la persecución política. Es por ello que poner en escena las líneas de ascenso, las relaciones y redes de poder debe ser parte del rol museal y su política estética. Marcar incomodidades, generar una participación activa que configure un tercer espacio dinámico. La ofensa no debe estar puesta en el modo de sentir sino en su evidencia como mecanismo de la propia lógica del capital que vela por un orden tranquilizador más que por la aprehensión de los procesos históricos como parte del ser ciudadano. Por tanto los esfuerzos no deberían estar puestos en controlar modos de transitar sino en promover la conexión entre pasado y presente, en la comprensión más amplia de los procesos de explotación, sumisión y sistematización de eliminación del otro, del abuso que persiste, que se reconvierte y muta para perpetuarse.

\section{REFERENCIAS}

Benjamin, W. (1975). El autor como productor. Traducción de Jesús Aguirre, Madrid, Taurus Ed.

Da Silva Catela, L. (2014). "Lo que merece ser recordado... Conflictos y tensiones en torno a los proyectos públicos sobre los usos del pasado en los sitios de memoria”, Clepsidra Vol 1 No 2 Buenos Aires, octubre 2014, pp. 28-47.

Da Silva Catela, L. (2006). "La materialidad de las memorias. Producción social de símbolos y usos del recuerdo frente a la violencia en Argentina”, Cuadernos de Antropología e Imagen, Vol 23: pp. 1-10.

de Sousa Santos, B. (2006). La Sociología de las Ausencias y la Sociología de las Emergencias: para una ecología de saberes. Buenos Aires, Clacso. Disponible en: http://biblioteca.clacso.edu.ar/clacso/coediciones/20100825033033/2C apituloI.pdf 
Deotte, J. L. (2007). “El museo no es un dispositivo”, disponible en: http://www.lauragonzalez.com/ImagenCultura /Deotte_2008_ElMuseoNoEsUnDispositivo.pdf

Gruner, E. (2005). La cosa politica o el acecho de lo real. Buenos Aires, Paidós.

Halbwachs, M. (2011). La memoria colectiva. Buenos Aires, Miño y Dávila.

Huyssen, A. (2000). "El parque de la memoria. Una glosa desde lejos", Punto de Vista No 68,Bs.As., año XXIII, pp 25-28.

Jelin, E., Langland V. (comp),(2003). Monumentos, memoriales y marcas territoriales. Madrid y Buenos Aires, Siglo XXI.

Pierre, N. (2008). Les lieux de la mémoire. Uruguay, Trilce.

Ranciere, J. (2014). El reparto de lo sensible. Estética y politica. Buenos Aires, Prometeo.

Ricoeur, P. (2008). La memoria, la historia y el olvido. Buenos Aires, Fondo de Cultura Económica.

Robin, R. (2014). "Sitios de memoria e intercambios de lugares", Clepsidra, Revista interdiscplinaria de Estudios sobre Memoria, Vol.1 Nro.2 disponible en: http://ppct.caicyt.gov.ar/index.php/clepsidra/article/view/Robin

Schindel, E. (2009). “Inscribir el pasado en el presente. Memoria y Espacio Urbano”, Revista Política y Cultura, N³1, pp. 65-87.

Williams, R. (1977/2009). Marxismo y literatura. Buenos Aires, Las Cuarenta.

\section{Notas}

1 Parte de estas reflexiones fueron presentadas en Cardoso, Noelia (2019) "Memoriales modernos sobre héroes y Terrorismo de Estado. Modos de transitar y construir la memoria colectiva del pasado reciente”, en Crenzel, E. Funes, $\mathrm{P}$ y Catoggio, S, mesa "Historia y memorias sociales sobre el pasado reciente en la Argentina”, XIII Jornadas de Sociología, Facultad de Ciencias Sociales, Universidad de Buenos Aires, CABA.

2 La inflexión permite señalar un punto que define el cambio de recorrido. En este caso, es una invitación a repensar los memoriales desde un perspectiva no tradicional

3 Título del informe final de la Comisión Nacional sobre la Desaparición de Personas (CONADEP) cuya expresión se cotidianizó para designar al límite social al Terrorismo de Estado. Dicha comisión fue creada en 1983 para investigar y registrar los crímenes y violaciones a los derechos humanos cometidos durante la última dictadura militar (1976-1983).

4 https://turismo.buenosaires.gob.ar/es/atractivo/parque-de-la-memoria

5 https://larepublica.pe/archivo/872724-rusia-carcel-para-jovenes-que-bailaron-twerking-frente-a-memorial-de-segund a-guerra-mundial

6 https://www.elperiodico.com/es/sociedad/20160714/pokemon-go-prohibido-museo-holocausto-auschwitzbirkenau- 5267245

7 https://www.bbc.com/mundo/noticias-38705447

8 https://elpais.com/diario/2010/12/07/opinion/1291676411_850215.html

9 Op.cit. 7.

10 La cita del Parque de la Memoria al inicio del texto es ejemplo de ello.

11 Parte de esta reflexión sobre el uso de las formas fue desarrollada en el artículo "Letra y música de una Nación imaginada" disponible en:

http://www.academia.edu/32597773/Letra_y_m\%C3\%BAsica_de_una_naci\%C3\%B3n_imaginada

12 Se hace referencia a cementerios y tumbas de civilizaciones antiguas en los principales centros turísticos en México, Perú, Egipto, retraducidos a "pintorescos" banal o comercial. 